\title{
Game Analysis on Subsidies of Alternative Rotation between Farmers and Governments in Main Grain Producing Areas in the Northeast
}

\author{
Zhang Dehua \\ Institute of Finance \\ Harbin University of Commerce \\ Harbin, China, 150028 \\ E-mail: zdh19841027@163.com
}

\begin{abstract}
The northeast is the national famous commodity grain production base, per capita amount of commodity grain in rural households in Heilongjiang and Jilin ranks the first and the second place respectively in the country. In the process of food growth production for nearly 10 years, main grain producing areas in northeast mainly rely on structural adjustment which achieves remarkable yield results. However, such increase also brings new problem"continuous cropping" for the northeast areas. The paper analyzes the related behaviors between farmers and governments using completed information dynamic game model and comes to the conclusion that the key influential factor on farmers' alternative rotation behaviors is the economic interest factor and the reasonable subsidy mechanism from governments helps to optimize farmers' behaviors. Finally, the paper proposes the following countermeasures and suggestions: implementing alternative rotation subsidies, strengthening supervision for subsidy payment, fostering deep processing industries to increase the added value of agricultural products, extending the period of land transfer to ensure effective land improvement for land operators.
\end{abstract}

Keywords- Main Grain Producing Areas in Northeast; Farmers; Governments; Alternative Rotation Subsidies

\section{INTRODUCTION}

In order to ensure national food security and increase farmers' income, the government implements the policy of food subsidies ${ }^{[1]}$. For the main grain producing areas, the policy of food subsidies mainly includes: direct grain subsidy, comprehensive agricultural subsidy, purchase of agricultural subsidy, improved seed subsidy and the minimum purchase price subsidy. The policy plays a boosting role in food production growth and farmers' income growth in main grain producing areas. Relatively speaking, the policy has obvious influence on food production growth ${ }^{[2]}$. Since 2004, China has achieved ten continuous increases in food production. However, through field research, we find that food production growth in northeast results from restructuring. Take Heilongjiang as an example, the traditional advantages crop-soybean and its sown area declines sharply during 10 years, which is replaced by the significant increase in the sown area of corn and rice ${ }^{[3]}$. Therefore, there exists the problem of crop rotation. In order to pursue high yield, most farmers choose corn and rice with higher profit. Rice planting involves the change from dry land to paddy fields. Once the field can be transformed successfully, the field can only plant rice; the replacing of corn and soybean is relatively simple, the farmers only need to change crop varieties. When the farmers choose corn, the majority of them will grow corn year after year with few rotations. Meanwhile, the farmers plant "continuous cropping" easily with large-scale land which is closely related to economic interests. The cost of rotation with large scale is relatively higher, the greater the loss of the interests is. After years of "continuous cropping" planting, output of land will be influenced which runs contrary to the long-term food security strategy of the nation. Considering the national food security interests, the paper discusses the feasibility of alternative rotation subsidies, analyzes the influence of alternative rotation behaviors from them, comes to some inspiration and proposes specific suggestions to implement them.

\section{GAME MODEL SELECTION AND CONSTRUCTION}

\section{A. Game Model Selection}

Generally speaking, government is the maker and implementer of policy which plays an active role in policy, while farmers implement agricultural production decisions after knowing the policy. Therefore, the process complies with the assumption of complete information dynamic game; the paper adopts complete information dynamic game researching the policy game between government and farmers ${ }^{[4]}$.

\section{B. The Extended Shape of Game Model}

The subjects of the game are the government and farmers. Policy subsidies are paid generally by local and central government which aim at ensuring the quality of farmland, so government represents local and central government in the process of game. Game subject specific strategies are as follows:

(1) Government policy set is \{ subsidy, no subsidy\}

(2) Farmers policy set is \{Alternative rotation, no Alternative rotation

As the following table is shown, the solid frame represents the game subject; the virtual frame represents 
the specific strategies of the game subject. According to the selection order and strategy set on both sides of game, the paper describes specific game information using dynamic game-shaped extensions. See the details are as follows:

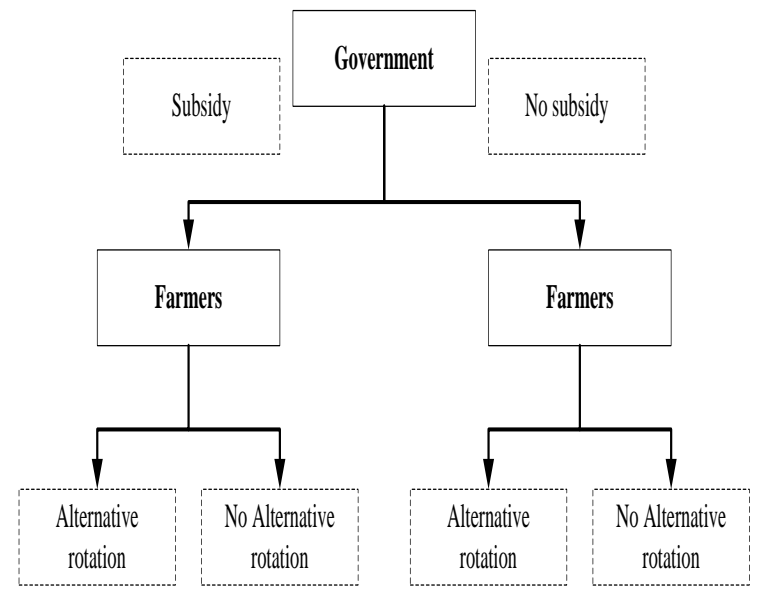

Figure 1 The Extended Shape of Dynamic Game between Government and Farmers

\section{GAME RELATIONS OF RELEVANT SUBJECTS}

\section{A. Assumptions of Game Model}

Before analyzing relevant earnings of game subjects, the paper has the assumptions for both sides of game subjects and sets relevant variables about earnings and costs of the game subjects. The basic assumptions and variables are as following:

Assumption 1: The government aims at increasing alternative rotation areas and obtaining eco-efficiency.

Assumption 2: Alternative rotation subsidies implemented by the government should be subsidized by the actual alternative rotation areas

Assumption 3: Subsidies have a positive impact on farmers' alternative rotation behaviors

Assuming that farmers' land area is S; assuming that farmers get net earnings of L2 with no alternative rotation land per unit and get net earnings of L1 with alternative rotation land per unit. Assuming that the government subsidizes $\mathrm{K}$ yuan for per unit of land; assuming when the government implement alternative rotation subsidies, the land proportion of alternative rotation for farmers is $\rho 1$; assuming when the government doesn't implement alternative rotation subsidies, the land proportion of alternative rotation for farmers is $\rho 2$; meanwhile, $\rho 1$ is greater than $\rho 2$; assuming that because farmers implement alternative rotation policy, ecological earnings per unit for government and farmers is $\eta 1$; assuming that because farmers doesn't implement alternative rotation policy, ecological loss per unit for government and farmers is $\eta 2$.

\section{B. Relevant Earnings Analysis on Game Subject Interest}

Among them, F (x) represents farmers' earnings function; $\mathrm{F}(\mathrm{y})$ represents government's earnings function. Under different strategies, the specific earnings between government and farmers are as follows:

$\mathrm{F}\left(\mathrm{x}_{1}\right)=\mathrm{K} \rho_{1} \mathrm{~S}+\eta_{1} \rho_{1} \mathrm{~S}-\eta_{2}\left(1-\rho_{1}\right) \mathrm{S}+\rho_{1} \mathrm{~S} \mathrm{~L}_{1}+\left(1-\rho_{1}\right) \mathrm{S} \mathrm{L}_{2}$

$\mathrm{F}(\mathrm{y} 1)=\eta_{1} \rho_{1} \mathrm{~S}-\mathrm{K} \rho_{1} \mathrm{~S}-\mathrm{C}$

$\mathrm{F}(\mathrm{x} 2)=\mathrm{S} \mathrm{L}_{2}-\eta_{2} \mathrm{~S}$

$F(y 2)=-\eta_{2} S-C$
$\mathrm{F}(\mathrm{x} 3)=\eta 1 \rho_{2} \mathrm{~S}-\eta_{2}\left(1-\rho_{2}\right) \mathrm{S}+\rho_{2} \mathrm{~S} \mathrm{~L} 1+\left(1-\rho_{2}\right) \mathrm{S} \mathrm{L}$

$\mathrm{F}(\mathrm{y} 3)=\eta 1 \rho_{2} \mathrm{~S}-\eta_{2}\left(1-\rho_{2}\right) \mathrm{S}$

$\mathrm{F}(\mathrm{x} 4)=\mathrm{SL}_{2}-\eta_{2} \mathrm{~S}$

$F(y 4)=-\eta_{2} S$

TABLE I. STRATEGY SELECTION AND EARNINGS ON BOTH SIDES

\begin{tabular}{|c|c|c|}
\hline $\begin{array}{c}\text { alternative } \\
\text { rotation } \\
\text { farmer }\end{array}$ & $\begin{array}{c}\text { implementing } \\
\text { alternative } \\
\text { rotation subsidy }\end{array}$ & $\begin{array}{c}\text { no implementing } \\
\text { alternative } \\
\text { rotation subsidy }\end{array}$ \\
\hline $\begin{array}{c}\text { no alternative } \\
\text { rotation }\end{array}$ & $\left(\mathrm{F}\left(\mathrm{x}_{1}\right), \mathrm{F}\left(\mathrm{y}_{1}\right)\right)$ & $\left(\mathrm{F}\left(\mathrm{x}_{3}\right), \mathrm{F}\left(\mathrm{y}_{3}\right)\right)$ \\
\hline
\end{tabular}

\section{Analysis on Game Process and Strategy Selection}

(1) Converting from low-yield crop to high-yield crop

Comparing $\mathrm{F}\left(\mathrm{x}_{1}\right)$ with $\mathrm{F}\left(\mathrm{x}_{2}\right)$, $\mathrm{F}\left(\mathrm{x}_{1}\right)-\mathrm{F}\left(\mathrm{x}_{2}\right)=$ $\mathrm{K} \rho_{1} \mathrm{~S}+\eta_{1} \rho_{1} \mathrm{~S}+\eta_{2} \rho_{1} \mathrm{~S}+\rho_{1} S L_{1}-\rho_{1} \mathrm{~S} \mathrm{~L}_{2}$. After conversion, $\mathrm{F}$ $\left(x_{1}\right)-F\left(x_{2}\right)$ can be converted into $K \rho_{1} S+\eta_{1} \rho_{1} S+\eta_{2} \rho_{1} S$ $+\rho_{1} \mathrm{~S}\left(\mathrm{~L}_{1}-\mathrm{L}_{2}\right)$. Among them, $\mathrm{K} \rho_{1} \mathrm{~S}$ represents alternative rotation subsidies paid by the government and is positive; $\eta_{1} \rho_{1} S$ represents ecological earnings and is positive; $\eta_{2} \rho_{1} S$ represents ecological loss and is positive. $S\left(\mathrm{~L}_{1}-\mathrm{L}_{2}\right)$ represents the gap between alternative rotation earnings and no alternative rotation earnings, because of the conversion from low-yield crop to high-yield crop, $\mathrm{L}_{1}$ is greater than $L_{2}$. That is, $L_{1}-L_{2}>0$. Finally, $K \rho_{1} S+\eta_{1} \rho_{1} S$ $+\eta_{2} \rho_{1} S+\rho_{1} S\left(L_{1}-L_{2}\right)>0, \quad F\left(x_{1}\right)$ is greater than $F\left(x_{2}\right)$. Therefore, farmers adopt alternative rotation strategy more likely and the government adopts corresponding strategy \{implementing alternative rotation subsidy \} and corresponding function is $\mathrm{F}\left(\mathrm{y}_{1}\right)$ (see Table II).

Comparing $F\left(x_{3}\right)$ with $F\left(x_{4}\right), F\left(x_{3}\right)-F\left(x_{4}\right)=\eta_{1} \rho_{1} S$ $+\eta_{2} \rho_{1} S+\rho_{1} S L_{1}-\rho_{1} S L_{2}$. After conversion, $F\left(x_{3}\right)-F\left(x_{4}\right)$ can be converted into $\eta_{2} \rho_{1} S+\eta_{2} \rho_{2} S+\rho_{2} S\left(L_{1}-L_{2}\right)$. Among them, $\eta_{1} \rho_{2} S$ represents ecological earnings and is positive; $\eta_{2} \rho_{2} S$ represents ecological loss and is positive. $\mathrm{S}\left(\mathrm{L}_{1}-\mathrm{L}_{2}\right)$ represents the gap between alternative rotation earnings and no alternative rotation earnings, because of the conversion from low-yield crop to high-yield crop, $\mathrm{L}_{1}$ is greater than $\mathrm{L}_{2}$. That is, $\mathrm{L}_{1}-\mathrm{L}_{2}>0, \mathrm{~F}\left(\mathrm{x}_{3}\right)$ is greater than $\mathrm{F}$ $\left(\mathrm{x}_{3}\right)$. Therefore, farmers adopt alternative rotation strategy more likely and the government adopts corresponding strategy \{no implementing alternative rotation subsidy and corresponding function is $\mathrm{F}\left(\mathrm{y}_{3}\right)$ (see Table II).

Comparing $F\left(y_{1}\right)$ with $F\left(y_{3}\right), F\left(y_{1}\right)-F\left(y_{3}\right)=\eta_{1}\left(\rho_{1}-\rho_{2}\right)$ $S+\eta_{2}\left(1-\rho_{2}\right) S-K \rho_{1} S-C$. In the formula, $\rho_{1}$ is greater than $\rho_{2}, \eta_{1}\left(\rho_{1}-\rho_{2}\right) S$ is positive and $\eta_{2}\left(1-\rho_{2}\right) S$ is positive. Through comparison, $F\left(y_{1}\right)$ is more $\eta_{1}\left(\rho_{1}-\rho_{2}\right) S+\eta_{2}\left(1-\rho_{2}\right)$ $\mathrm{S}$ than $\mathrm{F}\left(\mathrm{y}_{3}\right)$ on ecological earnings, meanwhile, $\mathrm{F}\left(\mathrm{y}_{1}\right)$ has more $\mathrm{K} \rho_{1} \mathrm{~S}+\mathrm{C}$ than $\mathrm{F}\left(\mathrm{y}_{3}\right)$ on subsidy and verification costs. The purpose of the government introducing subsidies is to get more ecological earnings and minimize the loss of it, meanwhile, the government subsidy has 
budget itself, so subsidies and management costs can be ignored by it and the government will choose the strategy with more ecological earnings. That is, the government chooses alternative rotation subsidies. Therefore, we can come to the conclusion that sub-game perfect Nash equilibrium of the game is implementing alternative rotation subsidy, alternative rotation .

TABLE II. STRATEGY SELECTIONS FROM GOVERNMENT

\begin{tabular}{ccc}
\hline $\begin{array}{c}\text { Government } \\
\text { strategy }\end{array}$ & $\begin{array}{c}\text { Government } \\
\text { earnings }\end{array}$ & $\begin{array}{c}\text { farmer strategy } \\
\text { selection }\end{array}$ \\
\hline $\begin{array}{c}\text { implementing } \\
\text { alternative } \\
\text { rotation } \\
\text { subsidy } \\
\text { no }\end{array}$ & $\mathrm{F}\left(\mathrm{y}_{1}\right)$ & alternative rotation \\
$\begin{array}{c}\text { implementing } \\
\text { alternative } \\
\text { rotation } \\
\text { subsidy }\end{array}$ & $\mathrm{F}\left(\mathrm{y}_{3}\right)$ & \\
\hline
\end{tabular}
crop

(2) Converting from high-yield crop to low-yield

(a) When $\mathrm{L} 2 \in(0, \eta 1+\eta 2+\mathrm{L} 1)$, comparing $\mathrm{F}(\mathrm{x} 1)$ with $F(x 2), F(x 1)-F(x 2)=K \rho 1 S+\eta 1 \rho 1 S+\eta 2 \rho 1 S$ $+\rho 1$ SL1- $\rho 1 S$ L2, we substitute L2 $=\eta 1+\eta 2+\mathrm{L} 1$ into the equation $F(x 1)-F(x 2)$ and get $F(x 1)-F(x 2)=K \rho 1 S$. $\mathrm{K} \rho 1 \mathrm{~S}$ is government subsidy and is greater than 0 , that is, $\mathrm{F}$ (x1) $-\mathrm{F}(\mathrm{x} 2)>0$. Therefore, farmers adopt alternative rotation strategy more likely and the government adopts corresponding strategy \{implementing alternative rotation subsidy and corresponding earnings function is $\mathrm{F}$ (y1) (see Table 3). Comparing F (x3) with F (x4), F (x3) -F (x4) $=\eta 1 \rho 1 \mathrm{~S}+\eta 2 \rho 1 \mathrm{~S}+\rho 1 \mathrm{SL} 1-\rho 1 \mathrm{~S}$ L2. When L $2<\eta 1+\eta 2+\mathrm{L} 1, \mathrm{~F}$ $(\mathrm{x} 3)$ is greater than $\mathrm{F}(\mathrm{x} 3)$. Therefore, farmers adopt alternative rotation strategy more likely and the government adopts corresponding strategy \{no implementing alternative rotation subsidy $\}$ corresponding earnings function is F (y3) (see Table III).

Comparing $\mathrm{F}$ (y1) with $\mathrm{F}$ (y3), according to the previous analysis, the government chooses the strategies with more ecological earnings, that is, implements alternative rotation subsidies. Therefore, we can come to the conclusion that sub-game perfect Nash equilibrium of the game is implementing alternative rotation subsidy, alternative rotation .

(b) When $\mathrm{L} 2 \in(\eta 1+\eta 2+\mathrm{L} 1, \mathrm{~K}+\eta 1+\eta 2+\mathrm{L} 1)$, comparing $\mathrm{F}(\mathrm{x} 1)$ with $\mathrm{F}(\mathrm{x} 2), \mathrm{F}(\mathrm{x} 1)-\mathrm{F}(\mathrm{x} 2)=$ $\mathrm{K} \rho 1 \mathrm{~S}+\eta 1 \rho 1 \mathrm{~S}+\eta 2 \rho 1 \mathrm{~S}+\rho 1 \mathrm{SL} 1-\rho 1 \mathrm{SL} 2$, when $\mathrm{L} 2<$ $\mathrm{K}+\eta 1+\eta 2+\mathrm{L} 1, \mathrm{~F}(\mathrm{x} 1)>\mathrm{F}(\mathrm{x} 2) ; \mathrm{L} 2<\mathrm{K}+\eta 1+\eta 2+\mathrm{L} 1$ includes $\mathrm{L} 2 \in(\eta 1+\eta 2+\mathrm{L} 1, \mathrm{~K}+\eta 1+\eta 2+\mathrm{L} 1)$, so when $\mathrm{L} 2 \in(\eta 1$ $+\eta 2+\mathrm{L} 1, \mathrm{~K}+\eta 1+\eta 2+\mathrm{L} 1), \mathrm{F}(\mathrm{x} 1)>\mathrm{F}(\mathrm{x} 2)$. Therefore, farmers adopt alternative rotation strategy more likely and the government adopts corresponding strategy \{implementing alternative rotation subsidy and corresponding earnings function is $\mathrm{F}$ (y1) (see Table 3). Comparing F (x3) with F (x4), F (x3) $-F(x 4)=\eta 1 \rho 1 S$ $+\eta 2 \rho 1 S+\rho 1 S L 1-\rho 1 S$ L2, when L2> $\eta 1+\eta 2+L 1$, $\eta 1 \rho 1 S$ $+\eta 2 \rho 1 S+\rho 1 S L 1-\rho 1 S$ L2 $<0$, that is, F (x3) <F (x4); L2> $\eta 1+\eta 2+\mathrm{L} 1$ includes $\mathrm{L} 2 \in(\eta 1+\eta 2+\mathrm{L} 1, \mathrm{~K}+\eta 1+\eta 2+\mathrm{L} 1)$, so when $\mathrm{L} 2 \in(\eta 1+\eta 2+\mathrm{L} 1, \mathrm{~K}+\eta 1+\eta 2+\mathrm{L} 1), \mathrm{F}(\mathrm{x} 3)>\mathrm{F}$ $(\mathrm{x} 4)$. Therefore, farmers adopt no alternative rotation strategy more likely and the government adopts corresponding strategy no implementing alternative rotation subsidy and corresponding earnings function is $\mathrm{F}$ (y4) (see Table III).

Comparing F (y1) with $\mathrm{F}(\mathrm{y} 4), \mathrm{F}(\mathrm{y} 1)=\eta 1 \rho 1 \mathrm{~S}-\mathrm{K} \rho 1 \mathrm{~S}$ $\mathrm{C}, \mathrm{F}(\mathrm{y} 4)=-\eta 2 \mathrm{~S}$. F (y4) represents no implementing subsidy policy. If the farmers choose no alternative rotation policy, the government will lose the ecological earnings of $\eta 2 S$. While it implements subsidy policy, the government will obtain the ecological earnings of $\eta 1 \rho 1 S$ and pay certain financial expenditure. The government pays more attention on the sustainable use of land relatively, so $\mathrm{K} \rho 1 \mathrm{~S}+\mathrm{C}$ can be ignored for $\eta 1 \rho 1 \mathrm{~S}$. With comparison, $\mathrm{F}(\mathrm{y} 1)>\mathrm{F}(\mathrm{y} 4)$ and the government will choose subsidy strategy. Therefore, we can come to the conclusion that sub-game perfect Nash equilibrium of the game is \{implementing alternative rotation subsidy, alternative rotation $\}$.

(c) When $\mathrm{L} 2 \in(\mathrm{K}+\eta 1+\eta 2+\mathrm{L} 1,+\infty)$, comparing $\mathrm{F}$ (x3) with $\mathrm{F}(\mathrm{x} 4), \mathrm{F}(\mathrm{x} 1)-\mathrm{F}(\mathrm{x} 2)=\mathrm{K} \rho 1 \mathrm{~S}+\eta 1 \rho 1 \mathrm{~S}+\eta 2 \rho 1 \mathrm{~S}$ $+\rho 1 \mathrm{SL} 1-\rho 1 \mathrm{~S}$ L2, when $\mathrm{L} 2>\mathrm{K}+\eta 1+\eta 2+\mathrm{L} 1, \mathrm{~K} \rho 1 \mathrm{~S}+\eta 1 \rho 1 \mathrm{~S}$ $+\eta 2 \rho 1 S+\rho 1 S L 1-\rho 1 S$ L2< 0 , that is, F (x1)<F (x2). Therefore, farmers adopt no alternative rotation strategy more likely and the government adopts corresponding strategy \{Implementing alternative rotation subsidy\} and corresponding earnings function is $\mathrm{F}$ (y2) (see Table 3 ). Comparing F (x3) with F (x4), F (x3) $-\mathrm{F}(\mathrm{x} 4)=\eta 1 \rho 1 \mathrm{~S}$ $+\eta 2 \rho 1 S+\rho 1 S L 1-\rho 1 S$ L2, when L2> $\eta 1+\eta 2+L 1, \eta 1 \rho 1 S$ $+\eta 2 \rho 1 S+\rho 1 S L 1-\rho 1 S$ L2 $<0$, that is, F (x3) $<F(x 4)$; L2 $>$ $\eta 1+\eta 2+\mathrm{L} 1$ includes $\mathrm{L} 2 \in(\mathrm{K}+\eta 1+\eta 2+\mathrm{L} 1,+\infty)$, when L2 $\in(\mathrm{K}+\eta 1+\eta 2+\mathrm{L} 1,+\infty), \mathrm{F}(\mathrm{x} 3)<\mathrm{F}(\mathrm{x} 4)$.

Therefore, farmers adopt no alternative rotation strategy more likely and the government adopts corresponding strategy $\{$ no implementing alternative rotation subsidy and corresponding earnings function is $\mathrm{F}$ (y4) (see Table III).

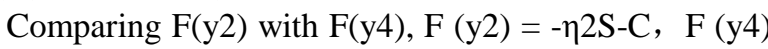
$=-\eta 2 S ; F(y 4)-F(y 2)=C, C$ represents the test costs of the government which is positive, so $\mathrm{F}(\mathrm{y} 4)-\mathrm{F}(\mathrm{y} 2)>0$ and the government chooses no implementing alternative rotation subsidy. We can come to the conclusion through backward induction that sub-game perfect Nash equilibrium of the game is \{no implementing alternative rotation subsidy, no alternative rotation $\}$.

The paper comes to the conclusion when converts from low-yield crop to high-yield crop, sub-game perfect Nash equilibrium of the game is implementing alternative rotation subsidy, alternative rotation $\}$. When converts from high-yield crop to low-yield crop, because of different range of L2, we can get two sub-game perfect Nash equilibriums. When $\mathrm{L} 2 \in(0, \mathrm{~K}+\eta 1+\eta 2+\mathrm{L} 1)$, sub-game perfect Nash equilibrium of the game is implementing alternative rotation subsidy, alternative rotation\}; when L2 $\in(\mathrm{K}+\eta 1+\eta 2+\mathrm{L} 1,+\infty)$, sub-game perfect Nash equilibrium of the game is no implementing alternative rotation subsidy, no alternative rotation $\}$. That is, under the condition of no alternative rotation, per unit earnings of crop L2 is lower than the total amount of per unit subsidy $\mathrm{K}$, per unit ecological benefit $\eta 1$, per unit ecological loss $\eta 2$ and per unit earnings of alternative rotation crop L1, sub-game perfect Nash equilibrium of the game is \{implementing alternative rotation subsidy, alternative 
rotation\}; on the contrary, sub-game perfect Nash equilibrium of the game is no implementing alternative rotation subsidy, no alternative rotation $\}$.

\begin{tabular}{|c|c|c|c|}
\hline $\begin{array}{c}\text { Gover } \\
\text { nment } \\
\text { strateg } \\
\mathrm{y} \\
\end{array}$ & $\begin{array}{l}\text { Government } \\
\text { earnings }\end{array}$ & $\begin{array}{c}\text { farmer } \\
\text { strategy } \\
\text { selection }\end{array}$ & condition \\
\hline subsidy & $\begin{array}{c}\mathrm{F}\left(\mathrm{y}_{1}\right)=\eta_{1} \rho_{1} \mathrm{~S}- \\
\mathrm{K} \rho_{1} \mathrm{~S}-\mathrm{C}\end{array}$ & $\begin{array}{c}\text { alternative } \\
\text { rotation }\end{array}$ & $\mathrm{L}_{2} \in\left(0, \quad \eta_{1}+\eta_{2}\right.$ \\
\hline $\begin{array}{l}\text { No } \\
\text { subsidy }\end{array}$ & $\begin{array}{c}F\left(y_{3}\right)=\eta_{1} \rho_{2} S-\eta_{2} \\
\left(1-\rho_{2}\right) S\end{array}$ & $\begin{array}{c}\text { alternative } \\
\text { rotation }\end{array}$ & $\left.+L_{1}\right)$ \\
\hline subsidy & $\begin{array}{c}F\left(y_{1}\right)=\eta_{1} \rho_{1} S- \\
K \rho_{1} S-C\end{array}$ & $\begin{array}{c}\text { alternative } \\
\text { rotation }\end{array}$ & $\mathrm{L}_{2} \in\left(\eta_{1}+\eta_{2}+\right.$ \\
\hline $\begin{array}{l}\text { No } \\
\text { subsidy }\end{array}$ & $F\left(y_{4}\right)=-\eta_{2} S$ & $\begin{array}{c}\text { no } \\
\text { alternative } \\
\text { rotation }\end{array}$ & $\begin{array}{c}\mathrm{L}_{1}, \quad \mathrm{~K}+\eta_{1}+\eta_{2}+ \\
\left.\mathrm{L}_{1}\right)\end{array}$ \\
\hline subsidy & $F\left(y_{2}\right)=-\eta_{2} S-C$ & $\begin{array}{c}\text { no } \\
\text { alternative } \\
\text { rotation }\end{array}$ & $\mathrm{L}_{2} \in\left(\mathrm{K}+\eta_{1}+\eta_{2}\right.$ \\
\hline $\begin{array}{l}\text { No } \\
\text { subsidy }\end{array}$ & $F\left(y_{4}\right)=-\eta_{2} S$ & $\begin{array}{c}\text { no } \\
\text { alternative } \\
\text { rotation }\end{array}$ & $\left.+\mathrm{L}_{1},+\infty\right)$ \\
\hline
\end{tabular}

\section{CONCLUSIONS}

(1) Whether farmers adopt rotation cropping or not depends on economic interests. Farmers are the actual rational economic men and chase higher economic interests which are their nature. Farmers will account alternative rotation cropping. If farmers think alternative rotation will bring great loss of their economic benefits, they will certainly not choose Alternative rotation. In contrast, farmers will definitely choose alternative rotation [5].

(2) In reality, land operation scale will have an impact on farmers' alternative rotation cropping ${ }^{[6]}$. In real research, land scale will have a significant impact on farmers' alternative rotation cropping. The scale factors don't play a role in alternative rotation in the model. The model supposes that we subsidize farmers according to the land operation areas and the farmers get the actual benefits, thus unit compensating rationalization is the key factor. However, in the real operations, the farmers obtain intensive operations in the form of subcontract, own limited contracted land and the existing subsidy is issued in accordance with the land tax areas, thus the farmers can't often obtain appropriate subsidies and subsidies are obtained by the original farmers (early land contractors). What's more, there doesn't have alternative rotation subsidy in real operations. The greater the size of alternative rotation is, the larger the loss is. Therefore, the size of land plays a limited role in alternative rotation cropping.

(3) The government implementing alternative rotation subsidy is necessary ${ }^{[7-10]}$. From the above analysis, we see when the government implements alternative rotation subsidies; the farmers will get the compensation of $\mathrm{K}$ unit per hectare. When $\mathrm{L} 2 \in(0, \mathrm{~K}+\eta 1+\eta 2+\mathrm{L} 1)$, sub-game perfect Nash equilibrium of the game is \{implementing alternative rotation subsidy, alternative rotation \}; when L2 $(\mathrm{K}+\eta 1+\eta 2+\mathrm{L} 1,+\infty)$, sub-game perfect Nash equilibrium of the game is no implementing alternative rotation subsidy, no alternative rotation $\}$. In essence, we should control the limitation of L2 and the growth of K can control L2 which will surpass the limitation of $K+\eta 1+\eta 2$ $+\mathrm{L} 1$. In other words, as long as subsidy can compensate the actual loss and most loss of the farmers, the final choice of the farmers will trend to alternative rotation.

\section{ACKNOWLEDGMENT}

The paper is funded by the following items. PhD Research Project Started of Harbin University of Commerce (14rw10). This paper is the phase progress of Philosophy and Social Science Project of Heilongjiang Province "Policy Combination and Supporting Measures of Rural Land Transfer (item number 14B115) ". This paper is supported by Science Research Foundation of Northeast Agricultural University (item number 2012RCB77). This paper is the phase progress of Philosophy and Social Science Project of Ministry of Education "Research on the Mechanism Innovation of Rural Land Transfer and Its Efficiency \& Income Distribution (item number 14YJC790125)"

\section{REFERENCES}

[1] Qiao Xuhua, Zhang Jianjie. Behavior orientation and policy effect of grain operation in main grain producing areas based on investigation in Henan $[\mathrm{J}]$. Research of Agricultural Modernization, 2008, 29(2):142-145.

[2] iang Jinqi, Zhao Hui. Agricultural price fluctuation and stable farmers' income in main grain producing areas [J]. Agricultural Economy, 2008(12): 93-94.

[3] Zhang Dehua, Zhou Huiqiu and Lou Sha. The problems and the countermeasures in food production in Heilongjiang [J]. Research of Agricultural Modernization. 2012(4):411-414.

[4] Lou Sha, Liu Huiping, Zhang Dehua. Comparative study on grain production and farmers' income coordination in Heilongjiang [J]. Research of Agricultural Modernization. 2013, Vol.34 (6):654-658

[5] Wang Peigang. Analysis on game path benefit subjects in current land expropriation [J]. Issues in Agricultural Economy, 2007(10):34-40.

[6] Zhou Qiren. Property and Institutional Change [M]. Beijing University Press, 2004.

[7] Zhang Dehua. Study on influential factors and countermeasures of farmers' income in Heilongjiang [M]. Harbin: Northeast Agricultural University, 2013.

[8] Cao Yukun, Chen Jiancheng, Chen Lirong. Game analysis on subject behaviors and policies in state-owned forest tenure reform in Yichun [J]. Issues in Agricultural Economy, 2010(5):89-95.

[9] A. T. Blake, A. J. Rayner, G. V. Reed. A Computable General Equilibrium Analysis of Agricultural Liberalisation: The Uruguay Round and Common Agricultural Policy Reform [J]. Journal of Agricultural Economies, 1999, Vol.50 (3): 400 - 424.

[10] Chul-Woo Kwon, Peter Orazem, Daniel Otto. Off-farm labor supply responses to permanent and transitory farm income $[\mathrm{J}]$. Agricultural Economics \& Resource Management, 2006, Vol.34 (1):59-67. 